\title{
Barack Obama e o Oriente Médio: Um Panorama Crítico (2009/2017) ${ }^{1}$ \\ Barack Obama and the Middle East: A Critical Overview (2009/2017)
}

\author{
DOI: $10.21530 /$ ci.v12n2.2017.656
}

Cristina Soreanu Pecequilo²

Clarissa Nascimento Forner ${ }^{3}$

\section{Resumo}

O objetivo deste artigo é apresentar um panorama crítico da gestão de Barack Obama de 2009 a 2017 em relação ao Oriente Médio, analisando os cenários estratégicos da região e as implicações para a Eurásia das ações estadunidenses. Para sustentar sua análise, o texto apresenta a trajetória do governo democrata, tendo como base um estudo sobre o legado de seu antecessor, George W. Bush, entre 2001 e 2009. Os principais temas abordados referem-se aos impactos dos atentados terroristas de 11/09/2001, com foco nas guerras do Afeganistão (2001/2014) e do Iraque (2003/2011), o processo de paz Israel-Palestina, as relações com o Irã, a Primavera Árabe, as crises na Síria e Líbia e a ascensão do Estado Islâmico. Observa-se a continuidade de um padrão de instabilidade regional e ambiguidade da estratégia dos Estados Unidos, assim como variações táticas entre as administrações republicana e democrata para a projeção de poder nesse espaço geopolítico e geoeconômico, que permanece essencial para os interesses do país.

Palavras-chave: Barack Obama; George W. Bush; Oriente Médio; Política Externa dos Estados Unidos

1 O artigo resulta de pesquisas desenvolvidas com apoio do CNPq e da CAPES.

2 Departamento de Relações Internacionais da Universidade Federal de São Paulo, em São Paulo/SP, Programa de Pós-Graduação em Relações Internacionais San Tiago Dantas (UNESP/UNICAMP/PUC), São Paulo/SP, Brasil, do Programa de Pós-Graduação em Economia Política Internacional/UFRJ, Rio de Janeiro/RJ, Brasil, e Pesquisadora NERINT/UFRGS, Porto Alegre/ RS, Brasil. E-mail: crispece@gmail.com

3 Bacharel em Relações Internacionais da Universidade Federal de São Paulo, em São Paulo/SP Programa de Pós-Graduação em Relações Internacionais San Tiago Dantas (UNESP/UNICAMP/PUC), São Paulo/SP, Brasil, Pesquisadora GEDES/UNESP e NEAI/UNESP, São Paulo/SP, Brasil.

Artigo submetido em 04/03/2017 e aprovado em 22/05/2017. 


\begin{abstract}
The goal of this article is to present a critical overview of Barack Obama's term from 2009 till 2017 in the Middle East, by analyzing the strategic scenarios of the region and the implications of US actions in Eurasia. In order to develop this analysis, the text presents the trajectory of the democratic government, by previously studying his predecessor legacy, George W. Bush from 2001 till 2009. The main issues addressed in this essay are the impacts of $9 / 11$ attacks, focusing on the Afghanistan (2001/2014) and Iraq (2003/2011) wars, the Arab Spring and the crisis in Syria and Lybia and the emergence of the Islamic State. A recurring pattern of regional instability can be seen, as well as the ambiguous strategy presented by the United States, as well as tactical variations between the republican and democratic administrations for projecting power in this geopolitical and geoeconomic space that remains pivot to the country's interests.
\end{abstract}

Keywords: Barack Obama; George W. Bush; Middle East; US Foreign Policy

\title{
Introdução
}

Geopolítica e geoeconomicamente, o Oriente Médio é uma das regiões mais sensíveis para os Estados Unidos (EUA), por sua localização geográfica, a sobreposição e reconstrução de fronteiras herdadas da era colonial, a competição entre potências estrangeiras extrarregionais por seus recursos energéticos e rotas de passagem e o reequilíbrio intrarregional entre poderes locais em busca de soberania e autonomia. Os norte-americanos alternaram ações de intervenção militar direta, ingerência político-econômica e esforços diplomáticos para projetar poder e estabelecer um mapa estratégico favorável à hegemonia.

Tais ações corresponderam a oscilações táticas, caracterizadas ou pela negligência e distanciamento ou pelo ativismo. No século XXI, tal situação foi agravada pelos atentados terroristas de 11/09/2001 aos EUA, atribuídos à Al-Qaeda, liderada por Osama Bin Laden. Em resposta, o republicano neoconservador ${ }^{4}$ George W. Bush desencadeou, em novembro daquele ano, a primeira operação militar da Guerra Global Contra o Terror (GWT) no Afeganistão, Estado identificado como

4 De acordo com Cooper (2011) e Singh (2009) não faltam dificuldades metodológicas ou consenso na definição do termo e agenda neoconservadora. A promoção da democracia, o internacionalismo unilateral e militarista fazem parte desses preceitos. Segundo os autores, ainda que W. Bush não tenha cumprido plenamente essa pauta, sua administração pode ser definida como neoconservadora, opção aqui compartilhada. Não é propósito do artigo analisar o termo neoconservador, recomendando-se Teixeira, 2007. 
santuário do terrorismo fundamentalista. Essa operação foi apenas o primeiro passo de transformações significativas no Oriente Médio e seu entorno.

Para os EUA, as consequências foram a superextensão imperial, crise econômica, fragmentações internas e perda de poder relativo ${ }^{5}$. Como sustenta Brzezinski (2012),

(...) a administração Bush demonstrou pouco interesse pelos cenários culturais complexos, rivalidades étnicas profundamente enraizadas, gerando conflitos dentro de conflitos, vizinhanças regionais perigosamente instáveis (...) e as disputas territoriais não resolvidas, todas as quais que severamente complicara as ações dos Estados Unidos no Afeganistão e Iraque e despertaram paixões anti-americanas regionais mais amplas (...) as consequências foram um declínio dramático na posição global da América (...) e (...) um resultado mais provável pode implicar um período inconclusivo de crise doméstica, combinada com a decadência abrangente da qualidade de vida na América, a infraestrutura nacional, a competitividade econômica e o bem estar social. (BRZEZINSKI, 2012, p. 67, 70, 73) ${ }^{6}$

Em 2009, tais fatores contribuíram para a eleição do primeiro presidente negro dos EUA, o democrata Barack Obama. Obama, cuja trajetória política caracterizou-se pela oposição a W. Bush, trouxe as propostas da mudança e da esperança. Isso se traduzia nas promessas de recuperação da economia, na inclusão social e na revisão das políticas unilaterais e militaristas de seu antecessor. Obama conseguiu cumprir tal agenda? Como lidou com o legado W. Bush? O objetivo do artigo não é trazer uma análise exaustiva da gestão Obama, mas sim um recorte: o estudo da agenda para o Oriente Médio. O texto encontra-se organizado em duas partes, uma síntese do legado W. Bush, seguida pela agenda de Barack Obama.

5 O conceito de superextensão imperial baseia-se em Kennedy (1989) e se refere ao descolamento entre as capacidades econômicas, político-estratégicas hegemônicas e a expansão de responsabilidades globais. A era W. Bush é apontada como uma das de maior endividamento financeiro e equívocos por analistas como Kissinger, 2014, Brzezinski, 2012 e Bandeira, 2016.

6 (...) the Bush administration showed little regard for the complex cultural settings, deeply rooted ethnic rivalries generating conflicts within conflicts, dangerously unsettled regional neighborhoods (...) and the unresolved territorial disputes, all of which severely complicated US actions in Afghanistan and Iraq and ignited wider regional anti-America passions (...) The consequences were a dramatic decline in America's global standing (...) one (...) more likely outcome could involve a period of inconclusive domestic drift, combining spreading decay in America's quality of life, national infrastructure, economic competitiveness, and social well-being (BRZEZINSKI, 2012, p. 67, 70, 73) 


\section{O Legado W. Bush: 0 11/09 e a GWT $(2001 / 2009)^{7}$}

Ao longo dos dois mandatos de W. Bush, poucas regiões foram tão afetadas política, econômica e socialmente quanto o Oriente Médio, devido à escalada acelerada da militarização e envolvimento norte-americano, justificada pelos atentados de 11/09 e a GWT. Segundo Gottlieb (2012), a GWT sustentou-se em quatro pilares: a diplomacia, a aplicação da lei contra os acusados de terrorismo, a força militar e os mecanismos econômicos (embargos, sanções e controles financeiros). Como sustenta Kitchen (2017), a GWT é multidimensional, e tanto W. Bush quanto Obama alternaram opções geopolíticas e geoeconômicas. Para o autor, não é possível afirmar que a geoeconomia se sobrepôs à geopolítica, sendo um dos instrumentos da GWT e não o preferencial. Ainda que tal projeção não fosse inédita, o período pós 2001 intensificou a ingerência com duas guerras: Afeganistão (2001/2014) e Iraque (2003/2011).

\section{o Terrorismo Transnacional e a Guerra Justa}

Sustentadas pela justificativa de combater o terrorismo islâmico transnacional, Iraque e Afeganistão inseriram-se em um processo de reposicionamento estratégico na Eurásia, considerada prioritária pelos neoconservadores desde 1989. O fim da Guerra Fria representava uma oportunidade de reconfigurar o mapa regional de forma mais favorável aos interesses dos EUA no Oriente Médio e na Ásia Central, em particular nesse último espaço, devido ao vácuo gerado pela antiga União Soviética (URSS).

A operação Tempestade do Deserto, a Guerra do Iraque (1990/1991), foi percebida como o primeiro passo nessa trajetória, e essas orientações foram previstas no Defense Planning Guidance (1992). Todavia, as ações do presidente George H. Bush, pai de W. Bush, caminharam no sentido contrário. O objetivo foi o de manter o status quo: o Iraque teve a sua soberania mantida, com o governo de Saddam Hussein, que nos anos 1980 aliara-se a Washington para combater a Revolução Islâmica de 1979 no Irã, e somente passara a ser inimigo devido à invasão do Kuwait para controlar as reservas de petróleo regionais. A saída de Hussein era vista como arriscada, pois geraria vácuos de poder. O mesmo raciocínio foi aplicado às relações com o Irã, a Síria, a Líbia, o Egito e as petromonarquias do Golfo Pérsico.

7 Ver Pecequilo, 2013. 
Embora Iraque, Irã, Líbia e Síria fossem definidas como "nações bandidas" (rogue states ${ }^{8}$ ), governadas por regimes autoritários, de caráter agressivo e com pretensões hegemônicas, com investimentos em programas de armas de destruição em massa e sem respeitar as convenções internacionais, as pressões mantinham-se no campo político. Tal estratégia permaneceu no governo de Bill Clinton (1993/2000), que alternou essa visão de continuidade com esforços de engajamento e contenção de Irã e Iraque.

No caso do Irã, uma tentativa de descongelamento foi realizada a partir de 1997, com a ascensão de Mohammad Khatami ao poder (SELIKTAR, 2012). No Iraque, manteve-se uma política de pressão com bombardeios aéreos sistemáticos e a aplicação de sanções político-econômicas. Ambas as políticas, guardadas suas diferenças, eram consideradas de apaziguamento pelos neoconservadores, e foram criticadas por W. Bush desde sua campanha eleitoral em 2000. Mesmo antes de 11/09, as duas opções já haviam sido abandonadas.

A mudança significativa aplicou-se ao processo de paz Israel-Palestina que, nos anos de 1980, entrara em uma fase de estagnação e retrocesso. Em choque com os interesses neoconservadores e do lobby israelense, Bush pai impulsionou uma solução negociada que retomava a agenda diplomática implementada (e depois abandonada) pelos EUA nos anos 1970: a troca da terra pela paz mediada pelos norte-americanos, com a devolução, por Israel, de territórios ocupados, e o reconhecimento da soberania desse Estado pelo interlocutor. Tal modelo de negociações resultara nos Acordos de Camp David entre Israel e Egito, em 1979, marco da estabilidade regional.

No pós Guerra Fria, a experiência repetiu-se com os Acordos de Oslo de 1993, implementados após um ciclo de negociações secretas em Madri, 1991. Iniciou-se um processo gradual de devolução de terras à Palestina e a suspensão da construção de colônias israelenses (Cisjordânia e Faixa de Gaza), a criação da Autoridade Nacional Palestina (ANP) como embrião do Estado palestino, conforme estabelecido pela resolução original das Nações Unidas de 1948, e o reconhecimento de Israel como Estado pelos palestinos. À frente do processo, estiveram H. Bush e depois Clinton, Ytzhak Rabin e Shimon Peres, por Israel, e Yasser Arafat, pela Palestina.

8 A outra categoria era nações falidas (failed states), desorganizadas politicamente, caracterizadas por guerras internas e potenciais santuários para ações terroristas (Afeganistão, Haiti, Somália). A partir de 2016, ambas as classificações de nações falidas e bandidas vêm sendo substituídas por "nações frágeis" (fragile states). Ver o Fragile States Index (2016) disponível em: < http://fsi.fundforpeace.org/ > . Acesso em: 20 fev. 2017.

9 Recomenda-se Visentini, 2014. 
De 1993 a 1995, o processo avançou, mas desmontou-se com o assassinato de Rabin por um radical israelense.

Em Israel, isso favoreceu a volta dos conservadores ao poder com Benjamin Nethanyahu (Bibi) ${ }^{10}$ (1996/1999). Tentativas de retomar o processo, como os Acordos de Wye Plantation (1998), não obtiveram sucesso e os atentados de 11/09 e a ascensão de W. Bush colocaram em xeque qualquer alternativa mediada. Essa estagnação foi mais um dos fatores da desorganização do Oriente Médio, ao qual se somaram a crescente violência, a instabilidade dos regimes, a ausência de desenvolvimento econômico e a exclusão social.

Ainda que muitos desses componentes fossem recorrentes pré 2001, a aceleração dos fenômenos foi resultado da projeção de poder dos EUA e levou à fragmentação de estruturas de poder, sociais e econômicas. 0 11/09 funcionou como uma válvula de escape para justificar as ações neoconservadoras e reativou a hipótese do choque civilizacional entre o Ocidente e o mundo islâmico, cujo embrião está na década de 1980 (BANDEIRA, 2016). Desde 1979, com a Revolução do Irã, mesmo antes da análise de Huntington que sistematizou o Choque das Civilizações, os EUA e a Europa Ocidental viram-se confrontadas pela “onda verde”, conhecida como a expansão do fundamentalismo islâmico (HALLIDAY, 2005) .

Entre 2001/2002 foram criados o Departamento de Segurança Doméstica (DHS) e o Comando Militar do Norte (USNORTHCOM), como parte do combate ao terrorismo, e foi editado o Ato Patriota (USA Patriot Act). Lei federal, o Ato Patriota validava medidas de exceção, como a prisão sem justificativa de suspeitos de terrorismo, a prática de tortura nas prisões militares do Iraque (Abu-Graib) e na base de Guantánamo. Havia crescente tolerância da população a tais práticas devido ao medo, o que somente alimentou globalmente comportamentos de extremo nacionalismo, racismo e xenofobia.

Para Daalder e Lindsay (2003), essas guerras faziam parte de uma agenda estratégica dos neoconservadores, que previa uma sequência de operações militares para consolidar o processo de mudança de regime nas potências não aliadas, visando o controle da Eurásia. O Afeganistão era o primeiro passo para tal domínio, mas que esbarrou nas dificuldades das operações em solo, na incapacidade dos EUA de implementar governos favoráveis à sua agenda, na resistência local e na triangulação sino-russo-indiana. O ponto de inflexão foi o fracasso no Iraque e o prolongamento de ambas as operações, que levou ao esgotamento moral, social e financeiro das tropas, forçando os neoconservadores a abandonar o plano de

10 Nethanyahu volta ao poder em 2009. 
intervenções sequenciais. Uma nova ação ocorreria somente na Líbia, em 2011.

Definida como "Guerra Justa", a guerra do Afeganistão representou o primeiro movimento militar da GWT. Vista como uma resposta à agressão de 11/09, conduzida pela Al-Qaeda, liderada por Bin Laden, que se encontrava protegido em solo afegão pelo governo dos Talibãs, a operação foi apoiada pela comunidade internacional. Sob o nome de "Operação Liberdade Duradoura", a ação foi referendada pela Resolução 1386 das Nações Unidas e contou com o auxílio financeiro, logístico e humano da Organização do Tratado do Atlântico Norte na forma da ISAF (International Security Assistance Force).

Em termos militares, a operação foi declarada bem-sucedida, ainda que as tropas da OTAN não tenham conseguido capturar Bin Laden ou as principais lideranças da Al-Qaeda. Isso levou à ampliação não oficial do conflito para a fronteira com o Paquistão, que se tornou um novo refúgio de forças fundamentalistas. O que ficou aparente não foi o cenário de fragmentação, e sim o sucesso político-militar. Entre 2002-2004 o país realizou eleições, levando Hamid Karzai ao poder, aliado do ocidente, seguidas pela implementação da Constituição, em 2005. Entretanto, tal processo de mudança de regime estava longe de estabilizar o país e de garantir direitos iguais a todos os cidadãos, especialmente às mulheres. Essas dificuldades eram acentuadas pela crescente instabilidade no Iraque (operação iniciada em 2003) e o aumento da insegurança no Ocidente, com os atentados de Madrid e Londres, em 2004 e 2005, que jogavam a opinião pública contra as operações militares.

Em 2006, a contínua deterioração da situação levou W. Bush a aumentar o número de soldados norte-americanos no Afeganistão. Os primeiros sinais da crise econômica, que eclodiria entre 2007/2008, levaram à derrota dos republicanos nas eleições de meio de mandato de 2006, e a crescentes pressões para que se estabelecesse um cronograma de retirada das tropas desse país e do Iraque. Mas como se chegou à Guerra do Iraque em 2003 e às demais crises?

\section{O Mapa da Estrada, o Eixo do Mal e a Guerra Preventiva}

Retomando a trajetória W. Bush, no caso do processo de paz, o mesmo representou a validação das posturas neoconservadoras em Israel, com Ariel Sharon ${ }^{11}$ à frente do governo entre 2001/2006 (seguido por Ehud Olmert de 2006 a 2008), devido à política pró Israel. Durante o governo Sharon, destacaram-se

11 Sharon foi acusado de liderar operações militares que resultaram em massacres de civis em Qybia (1953) e Sabra e Shatila (1982). Em 2000, sua visita à Esplanada das Mesquitas, local sagrado para os muçulmanos, iniciou uma forte onda de violência interna, e favoreceu o avanço conservador nas eleições em Israel. 
iniciativas como a construção do muro na fronteira (o "Muro Protetor"), a aceleração dos assentamentos nos territórios ocupados e a repressão sistemática à população palestina, com a tolerância do governo norte-americano (e as conhecidas condenações das Nações Unidas e internacionais). Em 2002, essa situação pareceu mudar: em meio à crescente violência e às pressões da comunidade internacional, instalou-se o Quarteto de Madrid, por meio do qual os EUA, a União Europeia, a Rússia e as Nações Unidas visavam retomar as negociações do processo de paz.

O Mapa da Estrada (Road Map) retomava a agenda de construção dos dois Estados, Israel e Palestina, propunha cessar fogo entre as partes, a devolução de territórios e a suspensão dos assentamentos de colonos. O projeto não alcançou nenhum resultado concreto. Outros fatos, que colocaram em xeque a agenda da paz, foram a morte de Yasser Arafat em 2004 (sucedido por Mahamud Abbas desde 2005) e o crescimento da influência política de grupos radicais como o Hamas. A vitória do Hamas em eleições na ANP, enfraquecendo o poder de Abbas, favoreceu as forças neoconservadoras em Israel e nos EUA, cuja política era a de não negociar com terroristas. Em linhas gerais, isso facilitou a destruição sistemática da ANP, situação que não se alterou na gestão de Obama.

Em 2002, essa iniciativa contrastava com a retórica agressiva de Bush com o lançamento do "Eixo do Mal”, que agrupava "Estados bandidos" que ameaçavam a sobrevivência norte-americana: Irã, Iraque e Coreia do Norte, seguidos por Líbia, Síria e Cuba. Apesar de nenhum representar um risco sistêmico, o clima de medo favorecia a construção de ameaças e de justificativas para intervenções militares. Nesse mesmo ano, foi lançada a Doutrina Bush, a Estratégia de Segurança Nacional (NSS) preventiva, que previa o ataque a alvos que ameaçassem a segurança norte-americana antes que essas nações se constituíssem em riscos iminentes. A NSS foi implementada na prática com a Guerra do Iraque. A despeito da oposição da comunidade internacional (com destaque ao "Eixo da Paz", formado por Moscou, Berlim, Paris), o Iraque foi atacado pelas forças norte-americanas, liderando a "Coalizão da Vontade".

A trajetória desse conflito demonstrou-se bastante controversa, com os EUA alegando que o país governado por Saddam Hussein era um risco. Todavia, nem aliados, e nem as Nações Unidas, validaram tal posição. Essa guerra não foi autorizada pelas Nações Unidas, apesar da existência da resolução 1441, que estabelecia que o Iraque sofreria "sérias consequências" em caso de não cumprir os mandatos da organização. Solidificava-se o exemplo de uma ação preventiva e unilateral, sendo o apoio mais significativo o do Reino Unido, liderado pelo 
primeiro-ministro Tony Blair. Posteriormente, W. Bush e Blair admitiram que os dados apresentados para sustentar a operação eram falsos, principalmente no que se refere à posse de armas de destruição em massa pelo Iraque.

A partir da guerra, o Iraque tornou-se um país cada vez mais fragmentado. Como no caso do Afeganistão, a vitória militar rápida, a captura em 2003 e o falecimento de Saddam Hussein em 2006, após sua condenação à morte pela justiça, não garantiram uma transição pacífica. Muito pelo contrário, realizaram-se, como indicam Daalder e Lindsay (2003), as avaliações do Departamento de Estado, que haviam impedido a derrubada de Hussein em 1991, e que foram retomadas antes da invasão de 2003: vácuo de poder, ampliando disputas internas pelo controle político do território.

Essa situação foi subestimada pelo governo W. Bush, que diminuiu as tropas após a primeira fase da operação “Choque e Terror” (Shock and Awe). Em 2006, isso levou a uma ofensiva militar (surge), seguido pelo início do desengajamento. Em 2008, foi assinado o Status of Forces Agreement, por W. Bush e o premiê Nouri al-Maliki, prevendo a retirada das tropas americanas do território até 2011. Seguindo o cronograma, a retirada parcial foi anunciada em 2010, com a manutenção de 50 mil homens em campo. Residualmente, as forças especiais, responsáveis por covert actions do Departamento de Defesa e da Central de Inteligência Americana (CIA), bem como as tropas mercenárias, financiadas por companhias privadas de segurança, continuaram atuando. A insuficiência desses esforços pós 2011, associada à fragmentação prévia, forneceram condições para a expansão do Estado Islâmico (EI).

Não se pode encerrar essa análise sem mencionar a política de estrangulamento contra o Irã, que resultou na aceleração do programa nuclear, associada à volta dos conservadores religiosos ao poder com Mahmoud Ahmadinejad, em 2005. De acordo com Kissinger (2014), esse processo deve ser encarado com normalidade, uma vez que é produto das pressões externas ao regime, ameaçando sua soberania e segurança. Como indica Waltz (2012), a “bomba iraniana” deveria ser compreendida como um fator muito mais de estabilidade do que de crise, pois reforça o poder de barganha do país e o equilíbrio regional ${ }^{12}$.

Como parte do processo, foram assinados acordos bilaterais com a Rússia no campo nuclear e se buscou reforçar uma agenda alternativa de relações internacionais com nações como a Venezuela, que se opunham a W. Bush. A questão

12 Tática similar é utilizada pela Coreia do Norte. 
nuclear iraniana, em 2010 e 2015, se tornaria um marco da gestão Obama. Em síntese, o legado W. Bush para o Oriente Médio preparou o terreno para muitos dos fenômenos e problemas que Obama precisaria administrar.

\section{A Gestão Obama: Da Ofensiva à Paciência Estratégica (2009/2017)}

A trajetória política de Barack Obama não pode ser descolada de seu discurso crítico aos efeitos que a GWT trouxera para os EUA: desrespeito aos direitos humanos, com apoio à tortura e práticas de exceção, como espionagem de cidadãos. Até a candidatura presidencial, Obama construiu sua plataforma em torno de ataques veementes a essa agenda, que depois assumiram um tom mais pragmático, centrado na promessa de encerrar a GWT e recuperar credibilidade. Tal credibilidade seria retomada por meio da reaproximação com os aliados, o apoio ao multilateralismo e aos esforços cooperativos para lidar com temas de segurança, assim como a atenção a questões sociais internas e da agenda global, tais quais direitos humanos e meio ambiente.

Essa análise não é consensual: de acordo com Kitchen (2017), o foco das críticas de Obama não era a GWT em si, mas somente a Guerra do Iraque, "contrasting the dumb war in Iraq, with the necessary war in Afghanistan" (KITCHEN, 2017). Outras oposições que se naturalizaram para definir ambas as guerras foram "war of choice" (guerra de escolha) para o Iraque, "war of need" para o Afeganistão, e a comparação entre as duas guerras do Iraque de 1991 e 2003, respectivamente de necessidade e escolha, conforme a leitura de Haas (2009).

Quinn (2017), em visão compartilhada por esse artigo, considera limitado afirmar que Obama apenas tinha como preocupação reafirmar sua posição contra o conflito no Iraque, e não o escopo da GWT. Segundo o autor,

Ele criticou a natureza aparentemente sem fim da "Guerra Contra o Terror" como uma estrutura legal e ideológica com base no fato de que ela conferia à presidência uma autoridade ampla e sem controle para o uso da força e a coleta de informações (...) Ele também criticou a administração por ter esvaziado o estoque de boa vontade internacional direcionada aos Estados Unidos devido sua tendência à confrontação e ao unilateralismo. (QUINN, 2017)13

13 He criticized the apparently open-ended nature of the "War on Terror" as a legal and ideological framework on the grounds that it conferred broad and unchecked authority on the presidency in the use of force and gathering of intelligence (...) And he chided the administration for having depleted the stock of international goodwill towards the United States through its penchant for confrontation and unilateralism. (QUINN, 2017) 
Apesar do apelo que tais questões tiveram em 2008, não foi essa agenda externa que garantiu a vitória eleitoral, e sim as consequências da crise econômica, que levaram o país à recessão. O empobrecimento e o desemprego e os rachas sociais raciais, étnicos e religiosos eram apenas alguns componentes desse cenário. Sustentado por sua juventude e figura carismática, e atrelado à imagem de "cidadão do mundo" e representante de uma América multirracial, Obama chegou à Casa Branca.

Em 2009, uma das principais preocupações foi promover uma mudança na retórica e no discurso de W. Bush, no qual se destacou o uso do termo "Poder Inteligente" (Smart Power). Criado por Joseph S. Nye Jr (2011), teórico que havia estabelecido as classificações de "Poder Duro" (Hard Power) e "Poder Brando" (Soft Power), nos anos de 1990, a ideia desse conceito era contrapor o estilo de Obama ao de seu antecessor: os EUA exerceriam uma liderança cooperativa, equilibrando força militar, ideológica e institucional. De acordo com Traub (2015) e Kitchen (2017), o termo, e a prática do conceito, tornaram-se usuais no governo Obama, tanto pelo presidente como pela secretária de Estado Hillary Clinton (2009/2013).

O uso do conceito representava uma iniciativa de reforço do poder ideológico ${ }^{14}$, ainda que não fosse um “documento oficial” estratégico. Em termos práticos, os primeiros documentos formais da "Doutrina Obama” foram apresentados em 2010, como indica Peter Dombrovsky (2012): o Quaddrennial Defense Review (QDR), a Nuclear Posture Review (NPT) e a Estratégia de Segurança Nacional (THE WHITE HOUSE, 2010).

Movido pelo contexto de deterioração da economia, Obama direcionou as energias do primeiro ano de governo à conclusão das intervenções no Oriente Médio. O presidente declarou o encerramento oficial da GWT, alterando a nomenclatura das operações a ela relacionadas para Overseas Contingency Operations. Como indicam Jackson e Tsui (2017), Obama passou a usar a expressão "guerra contra o extremismo violento” como preferencial. Como aponta Gottlieb (2012), “A mudança de perfil da estratégia global de contraterrorismo da América tem sido um dos esforços mais consistentes e, indiscutivelmente, bem sucedidos da administração em romper com o passado." (GOTTLIEB, 2012, p. 113)15

14 A utilização do termo "Poder Inteligente” é um dos exemplos do que Hoffmann (1977) definiu, no artigo clássico “An American Social Science: International Relations”, como a interação entre a "cozinha do poder e os salões acadêmicos” (HOFFMANN, 1977, p. 50).

15 "The rebranding of America's global counterrorism strategy has been the more consistent and arguably more successful of the administration's efforts to break from the past” (GOTTLIEB, 2012, p. 113). 
Segundo a NSS (WHITE HOUSE, 2010), a globalização impunha um leque amplo de ameaças à segurança, que não se restringiam ao terrorismo. Nesse sentido, seria improdutivo que seu gerenciamento consumisse todas as forças do país, como ocorrera em W. Bush: era preciso evitar generalizações e promover o engajamento de parceiros regionais, para evitar empreendimentos militares distantes. Ganharam destaque as questões sobre a interação dos EUA com os "novos centros de poder" (i.e as nações emergentes do Sul), a reconciliação com os aliados e a multipolaridade, além da segurança doméstica associada à reforma socioeconômica. Reiterou-se o compromisso com os direitos humanos, abolindo a tortura e as práticas de exceção de espionagem.

Até o fim do governo, Obama não conseguiu cumprir essas promessas: Guantánamo, continuou aberta, novas prisões secretas fora do território dos EUA foram denunciadas e as práticas de espionagem e demais medidas de exceção do Ato Patriota continuaram vigentes. Em 2015, o Ato Patriota foi substituído pelo Ato da Liberdade (USA Freedom Act), na sequência do escândalo das denúncias de Edward Snowden sobre as práticas ilegais da Agência Nacional de Segurança (NSA). Mantiveram-se as medidas de exceção, ainda que sob um discurso de maior transparência.

Em relação ao Oriente Médio, o turning point tático e estratégico ocorreu ainda em 2009, no discurso proferido no Cairo, Egito. Nesse discurso, fazendo uso de sua vivência pessoal e origens, Obama buscou uma reaproximação com o mundo muçulmano, comprometendo-se com a reconciliação e democratização da região. Exageros à parte, muitos apontaram esse discurso como um dos catalisadores da Primavera Árabe. Mais interessante é destacar que esse discurso foi proferido no Egito, ditadura até então apoiada pelos EUA, revelando os paradoxos tradicionais da retórica norte-americana.

Em 2011, esse discurso foi substituído por uma postura cuidadosa, à luz da Primavera Árabe que derrubava aliados norte-americanos nessas potências regionais, e dos desafios da retirada do Iraque e do Afeganistão. O período já abria as portas para as crises na Síria e na Líbia, e as situações complexas envolvendo o Irã e a questão Israel-Palestina. A esses temas, agregou-se a ascensão do EI, e a gestão de um quadro amplo de instabilidades. Em 2015, a necessidade de repensar essas dimensões e de não estender a presença na região levou à nova NSS (NSS-2015), conhecida pela "Paciência Estratégica”, ideia “interpretada" livremente como "don't do stupid stuff” (não faça coisas estúpidas). 


\section{A GWT: o Afeganistão, o Iraque, o Paquistão e o Estado Islâmico}

Iniciando sua agenda de encerramento da GWT, em 2009, no caso do Afeganistão e Paquistão, Obama realizou um encontro trilateral com os presidentes Hamid Karzai (Afeganistão) e Ali Zardai (Paquistão), reafirmando a parceria para o combate à Al Qaeda e o Talibã. O presidente anunciou um aumento de 30 mil efetivos em campo para o ano seguinte. (OBAMA, 2009) Foi aprovado, no Congresso, o projeto Kerry-Lugar-Berman, que previa o acréscimo de US\$ 1,5 bilhão/ano para a parceria com o Paquistão (HENDRICKSON, 2015). Com os aumentos progressivos, a quantidade de tropas no Afeganistão chegou a atingir o contingente de 100 mil efetivos, entre 2010 e 2011, ao passo que as perspectivas de encerramento real da guerra pareciam distantes.

Apesar das perdas de boots on the ground, o pilar da estratégia para o eixo AfPak era a utilização dos mecanismos de captura e bombardeios localizados, realizados por drones. Esses últimos já eram empregados no governo Bush e adquiriram maior impacto. Além de exercer o papel de vigilância, as aeronaves não tripuladas reduziam os custos econômicos e políticos da guerra, garantindo que menos soldados fossem enviados a campo. A contrapartida era que tais mecanismos não impediam o abatimento de civis e seu emprego culminava na violação da soberania e do espaço aéreo de outras nações. O episódio mais emblemático foi a operação realizada no Paquistão para a caça e captura de Osama Bin Laden, que foi morto em 2011.

As relações com o governo paquistanês foram abaladas, pois a operação não contou com um pedido de autorização prévio. Em resposta, a administração de Obama criticava o Paquistão16 por exercer um “jogo duplo”, auxiliando no combate ao Talibã, mas financiando outras redes terroristas como a rede Haqqani. Em alusão a essas relações, a então secretária de Estado Hillary Clinton declarou que: "Você não pode manter cobras no quintal e esperar que elas só mordam os inimigos”. (FINANCIAL TIMES, 2011)17

Em 2014, Obama assinou um acordo bilateral com o Afeganistão, prevendo a manutenção da cooperação estratégica e de um contingente de 10 mil homens no território “até o fim de 2024 e além disso” (ACKERMAN, 2014) ${ }^{18}$. Diante dessa

\footnotetext{
16 Para o mapeamento da situação geopolítica regional ver RIBEIRO e VIEIRA, 2016.

17 “You can’t keep snakes in your backyard and expect them only to bite your neighbours” (FINANCIAL TIMES, 2011). 18 "until the end of 2024 and beyond". (ACKERMAN, 2014)
} 
extensão, a guerra do Afeganistão se torna a mais longa da história norte-americana, apelidada como o "Vietnã de Obama” (GAGNON; HENDRICKSON, 2013).

No Iraque, o foco foi o cumprimento do Status of Forces Agreement. Em agosto de 2010, iniciou-se o processo de retirada das tropas de combate, finalizado em dezembro de 2011. Ainda que a retirada não tenha sido total, o Iraque só voltou ao topo das prioridades em 2014, por ocasião da tomada de territórios no país e na Síria pelo EI. Esse avanço na Síria era acompanhado pela ampliação das ações nas fronteiras próximas, incluindo Jordânia, Líbano, Arábia Saudita, o Irã e a Turquia. No Iraque, regiões estratégicas de produção de petróleo, estradas, fronteiras e represas passaram a ser controladas pelo EI entre 2013/2014. A conquista de Mosul, Tikrit e Faluja foram simbólicas desse avanço. Mas como se chega ao EI19 e ao seu projeto de construção e estabelecimento do "Califado Islâmico"?

Segundo Layne (2015), os desequilíbrios políticos e econômicos causados pela presença das tropas ocidentais facilitaram seu nascimento em meados de 2007, como ramificação da Al Qaeda. Somente após os levantes da Primavera Árabe e o início do conflito na Síria (2011), o grupo encontrou espaço para crescer e angariar novos territórios e seguidores. O EI utilizava táticas de extrema violência e com impacto midiático, como massacres de populações civis, decapitações e tortura, para assegurar sua expansão.

No Ocidente, isso se refletiu em ondas de atentados de pequeno e médio porte, alguns assumidos pelo EI, outros por seguidores de causas similares. Os atentados aconteceram tanto nos EUA (Boston) como em cidades como Paris e Nice, na França, Bruxelas, na Bélgica (cidade sede da OTAN), e Hannover, na Alemanha, entre 2013 e 2016.

Obama retomou os bombardeios ao Iraque, em 2014, sem consultar as Nações Unidas. Essas intervenções aéreas foram acompanhadas pela França, e alguns países como Alemanha e Reino Unido forneceram apoio logístico (participaram dos esforços países como Egito, Kuwait, Omã, Arábia Saudita, Qatar, Bahrein, Jordânia e Líbano). O auxílio às populações civis incluiu o fornecimento de alimentos, medicamentos e armamentos. Naquele ano, o presidente declarou guerra ao Estado Islâmico (OBAMA, 2014) e iniciou a elaboração do pedido de uma nova autorização para o uso da força militar (AUMF) ao Congresso, em 2015. Essa última estabelecia uma atuação limitada e defensiva, mas o debate sobre sua aprovação ficou travado no Legislativo. Enquanto isso, os avanços do exército

19 HARLING, 2017. 
de Bagdá em relação ao EI têm sido alcançados menos por influência e suporte norte-americanos e mais pela atuação das forças curdas Peshmerga e por milícias xiitas ligadas ao Irã (LAYNE, 2015).

A ineficiência e demora das ações ocidentais diante do EI, e as crises e desdobramentos do pós conflito iraquiano e afegão, associados à Primavera Árabe (ver item b), produziram um caos político regional. Somada aos fenômenos aqui relatados, não se pode deixar de mencionar a intensificação das ondas migratórias dessa região para a União Europeia, que passou a ser conhecida como "crise dos refugiados”. Tais ondas migratórias marítimas e terrestres geram inúmeras pressões à economia, sociedade e política europeias ${ }^{20}$, favorecendo o crescimento da extrema direita, que se opõe à recepção dos refugiados, criando profunda instabilidade na Turquia. A crise humanitária prosseguiu com Obama, e não parece ter sinais de reversão. Nos EUA, ela amplia, ao lado de outros fatores, a influência da direita, vide a plataforma do presidente republicano eleito Donald Trump.

Compartilhando das conclusões de Christopher Layne (2015), o que se argumenta é que os resultados de Obama na temática do combate ao terrorismo foram ambivalentes. Isso porque a redução dos contingentes militares em campo e o exercício da cooperação com aliados regionais não foram suficientes para encerrar os conflitos, posto que o presidente deu continuidade à atuação das tropas. Não há, como diz McCrisken (2011), um descolamento total em relação às condutas do governo Bush.

\section{A Primavera Árabe: Crise e Desdobramentos}

De todos os desdobramentos das relações com o Oriente Médio, a Primavera Árabe foi o mais inesperado para os cálculos estratégicos da administração Obama. Iniciados na Tunísia, em 2011, os levantes populares se alastraram por outros países, como Egito, Líbia e Síria. Na maioria dos casos, os processos de transição política sofreram retrocessos, por conta do retorno do autoritarismo e deflagração de guerras civis. O movimento era direcionado contra governos com os quais os EUA mantinham relações de longa data, o que dificultou, inicialmente, uma resposta mais proativa.

No caso egípcio, os protestos na Praça Tahrir fizeram com que, em fevereiro de 2011, o presidente declarasse apoio à transição política, a despeito das relações

20 O BREXIT, saída do Reino Unido da União Europeia, é um dos subprodutos dessas crises, uma vez que evidencia o componente nacionalista e xenófobo. 
de décadas conservadas com o governo de Hosni Mubarak. Após a queda desse último, os EUA desempenharam um papel mais ativo, oferecendo suporte ao processo eleitoral ocorrido no país em 2012, o qual deu o poder à Mohammed Morsi, um representante da Irmandade Muçulmana. Os eventos posteriores tomaram rumos inesperados: com menos de um ano de governo, Morsi sofreu um golpe da junta militar liderada por Abdel Fattah al-Sisi (atual governante do Egito). O presidente eleito em 2012 se encontra, até o presente, encarcerado e condenado à prisão perpétua por, de acordo com as declarações oficiais, ter contribuído com fugas de prisões e ataques a policiais no período das manifestações contra Mubarak.

Assim como no Egito, a Líbia passou por uma desestabilização política, agravada pela intervenção direta das potências ocidentais, em 2011. A violenta resposta do governo de Muammar Gaddafi às reverberações da Primavera Árabe no país levou à passagem da Resolução 1973 da ONU. Com 10 votos favoráveis e 6 abstenções (dentre elas, uma brasileira), a resolução autorizava o estabelecimento de no-fly zones na Líbia e permitia aos Estados membros: " to take all necessary measures... to protect civilians and civilian populated areas under threat of attack in [Libya], including Benghazi, while excluding a foreign occupation force of any form" (WEISSMAN, 2016, p. 673). Baseada no discurso humanitário da "Responsabilidade de Proteger", a operação Odissey Dawn consistiu em uma série de esforços militares nacionais, que levaram à captura e morte de Gaddafi e, posteriormente, foram transferidos à OTAN na renomeada operação Unified Protector. Diante do protagonismo europeu em ambas as investidas, um funcionário do serviço americano afirmou que a estratégia do país consistia em "liderar por trás”, angariando a Obama uma série de críticas, principalmente dos grupos conservadores.

Contrariando essa visão, Weissman (2016) afirma que os EUA desempenharam um papel relevante, oferecendo as tecnologias de ataques aéreos e vigilância, em posse da OTAN. Obama foi um importante apoiador da Resolução 1973. Após a queda de Gaddafi e o início das atividades ocidentais, a Líbia sucumbiu em desagregações políticas e conflitos entre milícias. Além do enfraquecimento do país, a violência ampliou os fluxos de refugiados na região, desencadeando a força de grupos extremistas no Mali e no Norte da África. (WEISSMAN, 2016)

Um dos símbolos do fracasso relativo da intervenção na Líbia foi a morte do Embaixador dos EUA no país em 2012, Christopher Stevens, em um ataque ao consulado em Benghazi (que vitimou mais cidadãos norte-americanos). A ausência 
de segurança ao corpo diplomático e a incapacidade das forças ocidentais de promover uma transição política na Líbia indicavam as limitações de ação dos EUA. Esse episódio, ocorrido com Hillary Clinton à frente do Departamento de Estado, foi utilizado por seus adversários na campanha presidencial de 2016, em particular por seu oponente republicano Donald Trump.

Em acréscimo ao desastroso histórico da "Primavera Árabe", a guerra civil na Síria, que completa, em 2017, seis anos, se tornou o "assunto não resolvido" da presidência. Apesar de declarar inúmeras vezes a necessidade de que o regime de Bashar al-Assad fosse retirado do poder e de apoiar financeiramente a atuação de grupos rebeldes e moderados anti-Assad, o presidente encerrou o segundo mandato dividindo opiniões acerca de sua decisão de não iniciar uma nova intervenção militar por terra. Pela perspectiva política, tal opção mantém coerência em relação às vozes da administração e da opinião pública doméstica, que rejeitavam a aplicação das forças militares em novo território. Do ponto de vista geopolítico, é encarada como fraqueza pela oposição conservadora, uma vez que o vácuo criado permitiu a atuação de outras potências, como Irã, Turquia²1 e Rússia22.

Critica-se a inação de Obama no caso sírio $^{23}$, e suas opções estratégicas pelo custo humanitário e implicações geopolíticas. Na visão de alguns grupos, as ações assemelham-se muito ao caso líbio, no qual se permitiu o avanço do EI ao enfraquecer o governo da situação (Assad), mesmo com seu autoritarismo. A ausência de uma avaliação clara sobre as forças em choque na Síria mantém o impasse no conflito, cujas negociações de paz se arrastam desde 2011, sem resultados concretos. Em 2016, as conversações foram suspensas após mais uma rodada de negociações em Genebra ${ }^{24}$, nas quais, além das potências ocidentais, a Rússia e as Nações Unidas, também foram incluídos o Irã e o governo Assad (em desagrado à oposição doméstica), antes considerado “inviável”. A Primavera Árabe e seus desdobramentos mantêm um quadro de instabilidade amplo. Contudo, foi essa mesma instabilidade que afetou as considerações estratégicas para o Irã.

21 A Turquia, pivô geopolítico entre o Ocidente e o Oriente, é um dos países mais atingido pelas crises regionais, como as guerras, ondas migratórias e disputas geopolíticas.

22 A Rússia recuperou protagonismo na Síria em 2015 quando iniciou intervenções aéreas contra o EI (para fortalecer a gestão Assad). Exerce papel relevante nas negociações de paz na Síria e em barrar uma intervenção militar terrestre do ocidente. O período é de pressão devido à crise da Ucrânia, em andamento desde 2014, e a situação síria reforçou simbolicamente o poder de iniciativa do Kremlin.

23 Para Smith (2016), Obama admitiu sentir-se responsável, em alguma medida, pelos massacres na Síria.

24 Para uma síntese recomenda-se Rocha, Julio e Graeff, 2016. 


\section{O Irã: Contenção e Negociação}

Para Obama, a pacificação do cenário pós GWT se encontrava ligado ao maior engajamento iraniano nas estratégias ocidentais, garantindo a cooperação e a contenção das aspirações nucleares de Teerã. À revelia da oposição republicana, o presidente sinalizou intenções de restabelecer os diálogos com o Irã, mesmo com Mahmoud Ahmadinejad no poder (SINGH, 2012). Em 2009, o diálogo EUAIrã foi pautado pelo foco de Washington nos direitos humanos, mas também pelo início das conversações entre os membros do P5 +1 (membros do Conselho de Segurança e Alemanha) e Irã, a respeito do programa nuclear.

Após a rejeição de uma proposta para o enriquecimento (a baixos níveis) do urânio iraniano na Rússia e na França, as sanções ao país foram retomadas, tanto multilateralmente quanto bilateralmente, pelos EUA e por países da União Europeia (UE). As medidas envolviam a limitação de transações econômicas com o Irã, bem como de transferência de armamentos e tecnologia ao país, o que, no interregno de 2010 a 2011, começou a afetar o bem-estar social da população. Em 2010, destaca-se o papel desempenhado pela diplomacia brasileira que, com auxílio turco, promoveu a negociação de um acordo tripartite com o Irã, aos moldes da proposta de 2009. O acordo foi rechaçado pelo Conselho de Segurança das Nações Unidas e novas sanções foram implementadas, via Resolução 1929 (SINGH, 2012).

De acordo com Amorim (2015), a participação brasileira e turca na negociação do Acordo de 2010 havia sido solicitada pelo governo democrata que percebia o processo das negociações multilaterais como travadas. Obama acreditava que, como parte da política de descongelamento, a negociação com o Irã era prioritária, mas que os interlocutores conhecidos, EUA, União Europeia e Nações Unidas, não poderiam conduzi-la com credibilidade. Nos EUA eram fortes os sinais de oposição a qualquer negociação com o Irã de ambos os partidos, democrata e republicano, devido às pressões do lobby israelense.

O Acordo Tripartite foi negociado pelas chancelarias turca e brasileira com o governo Ahmadinejad, mas, ao ser anunciado, foi rechaçado nos EUA, levando a administração Obama a retirar seu apoio. No Brasil, ano de eleições presidenciais, o acordo foi criticado pela oposição conservadora. Após essa oportunidade perdida, como destaca Amorim (2015), a questão iraniana retomou seu padrão de pressões ocidentais e recuo iraniano.

Porém, a Primavera Árabe, em 2011, reabriu o espaço regional para a ampliação da influência geopolítica iraniana, principalmente em Iraque e Síria (LAYNE, 
2015). A ascensão do EI nesses cenários contribuiu para reforçar tal importância estratégica do país que, apesar da crise econômica, sustentava sua condição política soberana e um regime estável. Os prospectos de cooperação se ampliaram em 2013, com a eleição do moderado Hassan Rouhani, com quem Obama travou a primeira conversa por telefone, após o rompimento das relações entre os países, em 1979.

Os diálogos entre o Irã e P5 + 1 floresceram. Apesar de sofrerem uma série de extensões em seus prazos, por conta de desacordos entre Teerã e o Ocidente acerca da retirada das sanções impostas ao país, em julho de 2015 o acordo final foi assinado, prescrevendo a limitação do número de centrífugas e da quantidade de urânio enriquecido no Irã e a retirada total das sanções econômicas.

Nos EUA, visando garantir a implementação do acordo e revogação das sanções, Obama assinou uma Ordem Executiva, em janeiro de 2016 (NATIONAL ARCHIVES, 2016), o que angariaria críticas domésticas (principalmente na bancada republicana do Congresso, majoritária desde 2014) e de aliados internacionais, que temiam as consequências geopolíticas da concretização do acordo. Entre esses últimos, a oposição mais veemente veio de Israel. O premiê Netanyahu chegou a discursar no Senado dos EUA contra o Acordo, simbólico do poder dos grupos de interesse israelenses no país.

\section{O Processo de Paz Israel e Palestina}

Embora existam muitos ruídos a respeito de um suposto afastamento entre EUA e Israel ao longo do governo Obama, a trajetória da relação especial não sofreu significativas alterações. Um exame pragmático do cenário geopolítico Israel-Palestina indica que o núcleo básico da questão continuou o mesmo: a estagnação do processo de paz, a permanência das políticas de Israel para os assentamentos em territórios ocupados, a progressiva contenção das ações de autonomia palestina e a destruição sistemática do que restou da ANP.

Houve, porém, discordâncias em tom e prática das gestões Obama e Netanyahu, devido às prioridades norte-americanas no entorno de Israel, que afetam os interesses dessa nação. Foram tais prioridades que levaram a essas acusações de afastamento, e que sinalizaram mais uma ambiguidade da gestão Obama, e da ausência de compromisso com uma solução negociada para a paz. Mas, afinal, em que consiste esse suposto conflito Obama e Israel?

Para Saltzman (2017), o estremecimento da "relação especial” EUA-Israel não se inicia a partir do acordo nuclear iraniano, apresentando sinais desde 2009, por 
conta das críticas de Obama à construção dos assentamentos israelenses. Após o icônico discurso democrata no Cairo, Netanyahu se demonstrou disposto a aceitar a solução de "dois Estados", mas impôs uma série de condicionantes, tais quais o reconhecimento de Jerusalém como capital de Israel e a desmilitarização da Palestina, o que contrariou a administração de Obama e esfriou ainda mais a relação bilateral (SALTZMAN, 2017).

Episódios como a Primavera Árabe e as negociações com o Irã apenas contribuíram para a intensificação dos desencontros. Netanyahu criticou o fato de Obama apoiar a derrubada de Hosni Mubarak, no Egito, um aliado norte-americano de longa data. A assinatura do acordo nuclear, por sua vez, foi a "gota d'água" para Netanyahu, que fez um inflamado discurso opositivo em uma sessão conjunta do Congresso americano, em 2015 (SALTZMAN, 2017).

A despeito de tais conflitos, Obama manteve seus compromissos com a segurança de Israel e com o lobby judaico, transferindo ao país mais armas e recursos que seus antecessores (SHLAIM, 2016). Em nenhum momento, o presidente apoiou iniciativas para a retomada do processo de paz. Chama atenção o fato de que a proposta do Mapa de Estrada, ainda na gestão W. Bush, foi a última tentativa concreta dos EUA de aparecerem como mediadores de novas negociações diplomáticas. Obama não apoiou o pedido de inclusão da Palestina como membro pleno da ONU, iniciado por Abbas em 2011, tendo em vista que essa ação traria como pressuposto o reconhecimento formal da Palestina como Estado.

Por outro lado, em dezembro de 2016, os EUA garantiram, com uma abstenção, a passagem de uma resolução no CSONU que condenava a política de assentamentos e determinava o estabelecimento de um Estado independente palestino com capital em Jerusalém. Obama autorizou unilateralmente o envio de uma ajuda de US\$ 221 milhões à ANP (BUSINESS INSIDER, 2017), contrariando o Congresso. Apesar dessa postura aparentemente pró Palestina, a ausência de um esforço diplomático concentrado, com metas claras, indica a estagnação de um processo de paz concreto e a falta de perspectivas de uma solução mediada.

\section{Conclusões}

Em World Order, Kissinger (2014) afirma que a compreensão do legado de qualquer líder depende de uma avaliação de médio e longo prazo dos impactos de suas decisões. Visão similar é trazida por Bentley e Holland (2017), ao afirmar 
que os resultados da Doutrina Obama serão "consequenciais". Entretanto, isso não exime o analista de apresentar um panorama tanto temático quanto crítico da gestão que findou em janeiro de 2017, dando lugar à administração de Donald Trump e sua retórica do Make America Great Again. Assim como Obama explorou as fragilidades da era W. Bush, o mesmo se repetiu com Trump.

Para Quinn (2017), "mesmo com o risco de apontar uma realidade banal, todas as administrações representam uma combinação de continuidade e mudança. Ninguém começa o mundo de novo.”25

No campo da continuidade, Obama não promoveu um pleno desengajamento do Oriente Médio, uma vez que o encerramento oficial das guerras do Iraque e do Afeganistão foi precedido por acordos bilaterais com ambos para a manutenção de efetivos norte-americanos em solo. Isso não impediu a expansão do EI, que cresceu na fragmentação gerada pelas operações estadunidenses e pelas disputas internas em países como Iraque, Síria, Líbia, dentre outros. No que se refere à descontinuidade, inserem-se a mudança da retórica da GWT, o incremento do uso de táticas multilaterais, drones e a mudança diante do Irã. Segundo Kitchen (2017),

(...) o contraterrorismo se expandiu por meio da Guerra do Iraque, passando a incluir uma tentativa de reorganizer o Oriente Médio na totalidade. Esse novo imperativo abrangente da política dos Estados Unidos foi buscado majoritariamente com ferramentas militares (...) No Oriente Médio, a geografia original da Guerra Contra o Terror, da qual Obama tentou afastar os Estados Unidos, foi renovada depois da Primavera Árabe em um novo e transformado mapa regional. (KITCHEN, 2017) ${ }^{26}$

Em nenhum momento, Obama deu sinais de que o Oriente Médio deixaria de ser prioritário, confirmando avaliações como a de Bandeira (2016), de que o país não abrirá mão dessa região como pivô geopolítico. Para isso, como observam Jackson e Sui (2017), estratégias e táticas mesclaram tanto evolução quanto adaptação. Uma mescla que não gerou estabilidade ou impediu o spill-over da violência no Oriente Médio e seus subprodutos, como a crise dos refugiados, a crescente xenofobia e a expansão do nacionalismo.

25 "At risk of signalling a banal truth, all administrations represent a combination of continuity and change. No one gets to begin the world again”. (Quinn, 2017)

26 (...) counterterrorism was expanded through the Iraq War to encompass an attempt to comprehensively reorder the Middle East. This new overaching imperative of US foreign policy was pursued with overwhelming military tools (...) In the Middle East, the original geography of the War on Terror that Obama had sought to reroute the United States away was renewed post-Arab Spring in a new and shifting map of the region. (KITCHEN, 2017) 


\section{Referências}

ACKERMAN, Spencer. New Afghanistan pact means America's longest war will last until at least 2024. The Guardian. 30 set. 2014. Disponível em: < https://www. theguardian.com/world/2014/sep/30/us-troops-afghanistan-2024-obama-bilateralsecurity-agreement > . Acesso em: 20 jan. 2017.

AMORIM, Celso. Teerã, Ramalá e Doha- memórias da política externa ativa e altiva. Rio de Janeiro: Benvirá. 2015.

BANDEIRA, Luiz Alberto Moniz. A desordem mundial- o espectro da total dominação. Civilização Brasileira: Rio de Janeiro. 2016.

BENTLEY, Michelle and HOLLAND, Jack. "Introduction" in BENTLEY, Michelle and HOLLAND, Jack (ed). The Obama doctrine - a legacy of continuity in US foreign policy?. London and New York: Routdlege. 2017.

BRZEZINSKI, Zbigniew. Strategic vision. New York: Basic Books. 2012.

BUSINESS INSIDER. Why Obama sent the Palestinians \$221 million during his last hours in office". 24 jan. 2017. Disponível em: < http://www.businessinsider.com/obamaqueitly-sends-221-million-to-palestine-2017-1 > . Acesso em: 29 jan. 2017.

COOPER, Danny. Neoconservantism and American foreign policy. London and New York: Routledge. 2011.

DAALDER, Ivo H.; LINDSAY, James M. America unbound. Washington: Brookings Institution. 2003.n

DOMBROWSKI, Peter. Renewing US National Security Policy- something old, something new. In: HOOK, Steven; SCOTT, James M. (ed). American renewal? Washington: CQ Press. 2012.

FINANCIAL TIMES. Clinton warns Pakistan on militant 'snakes'. 21 out. 2011. Disponível em: < https://www.ft.com/content/93147c90-fbc7-11e0-9283-00144feab49a > . Acesso em: 20 jan. 2017.

FRAGILE STATES INDEX. 2016. Disponível em http://fsi.fundforpeace.org/. Acesso em: 20 fev. 2017.

GOTTLIEB, Stuart. Change and continuity in America's counterterrorism strategy under Obama. In: HOOK, Steven; SCOTT, James M. (ed) American renewal? Washington: CQ Press. 2012.

GAGNON \& HENDRICKSON, Frédérick, Ryan C. The United States versus Terrorism: From the Embassy Bombings in Tanzania and Kenya to the Surge of forces in Afghanistan. In: CARTER, Ralph G. (org). Contemporary Cases in US foreign policy. 5 ed, California: SAGE, 2013, p. 11- 40. 
HAASS, Richard. War of necessity-War of choice- a memoir of two Iraq wars. New York: Simon and Schuster 2009.

HALLIDAY, Fred. The Middle East in International Relations- power, politics and ideology. Cambridge University Press: Cambridge. 2005.

HARLING, Peter. “Estado Islâmico, um monstro providencial”. Disponível em: http://diplomatique.org.br/estado-islamico-um-monstro-providencial/. Acesso em: 15 jan. 2017.

HENDRICKSON, Ryan C. Obama at war. Congress and the imperial presidence. Kentucky: The University Press of Kentucky, 2015.

HOFFMANN, Stanley. An American Social Science: International Relations. Daedalus, Vol. 106, No. 3, Discoveries and Interpretations: Studies in Contemporary Scholarship, Volume I, Summer, 1977, p. 41-60.

JACKSON, Richard;TSUI, Chin-Kuei. War on terror II- Obama and the evolution of US counterterrorism. In: BENTLEY, Michelle;HOLLAND, Jack (ed). The Obama Doctrinea legacy of continuity in US foreign policy?. Routledge: New York. 2017.

KENNEDY, Paul. Ascensão e queda das grandes potências. Rio de Janeiro: Campus. 1989. KISSINGER, Henry. World Order. Penguin Press: New York. 2014.

KITCHEN, Nicholas. Ending permanent war- security and economy under Obama. In: BENTLEY, Michelle; HOLLAND, Jack (ed). The Obama Doctrine- a legacy of continuity in US foreign policy?. Routledge: New York. 2017.

LAYNE, Christopher. Obama's missed opportunity to pivot away from the Middle East. Insight Turkey. Vol. 17, N 3, 2015.

MCCRISKEN, Trevor. Ten years on: Obama's war on terrorism in rhetoric and practice. International Affairs, vol. 87, $\mathrm{n}^{\circ} .4,2011, \mathrm{p} .781-801$.

NATIONAL ARCHIVES. “Executive Order 13716 of January 16, 2016”. Disponível em: < https://www.gpo.gov/fdsys/pkg/FR-2016-01-21/pdf/2016-01325.pdf > .Acesso em: 20 jan. 2017.

NYE JR, Joseph S. The future of power. New York: Public Affairs, 2011.

OBAMA, Barack. “The New Way Forward - The President's Address”. White House, 1 dez. 2009. Disponível em: < https://obamawhitehouse.archives.gov/blog/2009/12/01/ new-way-forward-presidents-address > .Acesso em: 20 jan. 2017.

OBAMA, Barack. President Obama: "We Will Degrade and Ultimately Destroy ISIL”. 10 set. 2014. Disponível em: < https://www.whitehouse.gov/blog/2014/09/10/presidentobama-we-will-degrade-and-ultimately-destroy-isil > .Acesso em: 3 set. 2015.

PECEQUILO, Cristina Soreanu. Os EUA e o século XXI. Rio de Janeiro: Elsevier, 2013.

QUINN, Adam. Restraint and constraint- a cautious president in a time of limits. In: BENTLEY, Michelle; HOLLAND, Jack (ed). The Obama Doctrine- a legacy of continuity in US foreign policy?. Routledge: New York. 2017. 
RIBEIRO, Erik Herejk e VIEIRA, Maria Gabriela. “Índia e Paquistão na Organização para a Cooperação de Xangai: a busca por estabilidade política e integração na Ásia”. Boletim de Conjuntura Nerint, 1 (3), Novembro 2016. p. 7-14. Disponível em https://www.ufrgs.br/ nerint/wp-content/uploads/2016/12/POR-Ribeiro-Vieira.pdf. Acesso em: 20 fev. 2017. ROCHA, Douglas de Quadros; JULIO, Isabela Souza; GRAEFF, Patrícia. As conversações de paz sobre o principais avanços e diferenças entre as reuniões de Viena (2015) e Genebra III (2016). Boletim de Conjuntura Nerint, vol. 1, $\mathrm{n}^{\circ}$. 1, Julho. 2016, p. 5-13. Disponível em https://www.ufrgs.br/nerint/wp-content/uploads/2016/07/Boletimv1n1-transicaopoliticamianmar.pdf. Acesso em: 20 fevereiro 2017.

SALTZMAN, Ilai Z. Not So "Special Relationship”? US-Israel Relations During Barack Obama’s Presidency. Israel studies, vol. 22, n. 1, 2017.

SELIKTAR, Ofira. Navigating Iran-From Carter to Obama. New York: Palgrave Macmillan. 2012 .

SHLAIM, Avi. Barack Obama, John Kerry, and the Palestine saga. Al Jazeera. 24 dez. 2016. Disponível em: < http://www.aljazeera.com/indepth/opinion/2016/12/barack-obamajohn-kerry-palestine-saga-161224101744800.html > .Acesso em: 20 jan. 2017.

SINGH, Robert. Neoconservantism- theory and practice. In: PARMAR, Inderjeet; MILLER, Linda B.; LEDWIDGE, Mark (ed). New directions in US Foreign Policy. London and New York: Routledge. 2009.

SINGH, Robert. Barack Obama's Post-American foreign policy: the limits of engagement. New York: Bloomsbury, 2012.

SMITH, David. Obama reflects on Syria at farewell press conference: 'I always feel responsible'. The Guardian. 2016. Disponível em: < https://www.theguardian.com/ us-news/2016/dec/16/obama-syria-assad-aleppo-final-press-conference > . Acesso em: 20 jan. 2017.

TEIXEIRA, Carlos Gustavo Poggio. Quatro temas fundamentais do pensamento neoconservador em política externa. Rev. bras. polít. int., Brasília, v. 50, n. 2, Dec. 2007, p. 80-96. Disponível em: < http://www.scielo.br/scielo.php?script = sci_arttext\&pid $=$ S0034-73292007000200006\&lng $=$ en\&nrm $=$ iso $>$. Access on 14 Apr. 2017.

TRAUB, James. The Hillary Clinton doctrine. 2015. Disponível em: http://foreignpolicy. com/2015/11/06/hillary-clinton-doctrine-obama-interventionist-tough-mindedpresident/. Acesso em: 10 jun. 2016.

THE WHITE HOUSE. "National Security Strategy”. Washington, 2010. Disponível em: < http://www.whitehouse.gov/sites/default/files/rss_viewer/national_security_ strategy.pdf > .Acesso em: 10 jun.2013.

THE WHITE HOUSE. “National Security Strategy”. Washington, 2015. Disponível em: < http://www.whitehouse.gov/sites/default/files/docs/2015_national_security_ strategy.pdf\&gt; Acesso em: 12 fev. 2015. 
VISENTINI, Paulo Fagundes. O grande Oriente Médio. Rio de Janeiro: Ed. Elsevier, 2014. WALTZ, Kenneth. Why Iran should get the bomb. Foreign Affairs, vol. 91, nº. 4, July/ August 2012. p. 2-5.

WEISSMAN, Stephen R. Presidential Deception in Foreign Policy Making: Military Intervention in Libya 2011. Presidential Studies Quarterly, Vol. 46, No. 3, September 2016, 669-690. 